\title{
Effectiveness and safety of carbohydrate counting in the management of adult patients with type 1 diabetes mellitus: a systematic review and meta-analysis
}

Eliege Carolina Vaz', Gustavo José Martiniano Porfírio², Hélio Rubens de Carvalho Nunes ${ }^{3}$, Vania dos Santos Nunes-Nogueira'

\begin{abstract}
Objective: This study aimed to evaluate the effectiveness and safety of carbohydrate counting $(\mathrm{CHOC})$ in the treatment of adult patients with type 1 diabetes mellitus (DM1). Materials and methods: We performed a systematic review of randomized studies that compared $\mathrm{CHOC}$ with general dietary advice in adult patients with DM1. The primary outcomes were changes in glycated hemoglobin (HbA1c), quality of life, and episodes of severe hypoglycemia. We searched the following electronic databases: Embase, PubMed, Lilacs, and the Cochrane Central Register of Controlled Trials. The quality of evidence was analyzed using the Grading of Recommendations Assessment, Development and Evaluation (GRADE). Results: A total of 3,190 articles were identified, and two reviewers independently screened the titles and abstracts. From the 15 potentially eligible studies, five were included, and 10 were excluded because of the lack of randomization or different control/ intervention groups. Meta-analysis showed that the final $\mathrm{HbA} 1 \mathrm{c}$ was significantly lower in the $\mathrm{CHOC}$ group than in the control group (mean difference, random, $95 \% \mathrm{Cl}:-0.49(-0.85,-0.13), \mathrm{p}=0.006)$. The meta-analysis of severe hypoglycemia and quality of life did not show any significant differences between the groups. According to the GRADE, the quality of evidence for severe hypoglycemia, quality of life, and change in $\mathrm{HbA} 1 \mathrm{c}$ was low, very low, and moderate, respectively. Conclusion: The meta-analysis showed evidence favoring the use of CHOC in the management of DM1. However, this benefit was limited to final $\mathrm{HbA} 1 \mathrm{c}$, which was significantly lower in the $\mathrm{CHOC}$ than in the control group. Arch Endocrinol Metab. 2018;62(3):337-45
\end{abstract}

Keywords

Type 1 diabetes mellitus; carbohydrate counting; quality of life; systematic review; meta-analysis
1 Departamento de Clínica Médica,

Faculdade de Medicina de Botucatu, Universidade Estadual de São

Paulo (Unesp), Botucatu, SP, Brasil ${ }^{2}$ Centro Cochrane do Brasil,

Disciplina de Medicina de Urgência e Medicina Baseada em Evidências, Universidade Federal de São Paulo (Unifesp), São Paulo, SP, Brasil

${ }^{3}$ Departamento de Saúde Pública,

Faculdade de Medicina de Botucatu, Universidade Estadual de São

Paulo (Unesp), Botucatu, SP, Brasil

Correspondence to:

Vania dos Santos Nunes Nogueira Departamento de Clínica Médica,

Faculdade de Medicina de Botucatu, Universidade Estadual de São Paulo Av. Prof. Mário Rubens

Guimarães Montenegro, s/ $n^{\circ}$

Unesp, Campus de Botucatu

18618-687 - Botucatu, SP, Brasil

vsnunes@fmb.unesp.br

Received on Jun/5/2017 Accepted on Feb/7/2018

DOI: $10.20945 / 2359-3997000000045$

\section{INTRODUCTION}

$\mathrm{D}$ iabetes mellitus (DM) comprises a heterogeneous group of metabolic disorders that commonly feature hyperglycemia, which results from disturbances in insulin secretion, insulin action, or both (1). In most cases, type $1 \mathrm{DM}$ (DMl) is an autoimmune disease characterized by the destruction of insulin-producing beta cells, accounting for $5 \%$ to $10 \%$ of all DM cases (1). In Brazil, eight of every 100,000 people under the age of 20 have DMl (2).

The therapeutic treatment and control of DMl includes the use of insulin for glycemic control, balanced diet, and regular physical activity. Daily insulin requirements vary based on age, diet, patient self-monitoring of blood glucose and daily routines.
Glycemic control of patients with DM is important because it impacts the development of diabetic complications (3). Diabetes control is evaluated mainly according to the levels of HbAlc, fasting blood glucose, and postprandial blood glucose (blood glucose measured two hours after meal consumption). Borderline normal values without the risk of hypoglycemia, impaired mental status, and patient welfare indicate good glycemic control (4).

The American Diabetes Association recommends the following levels for nonpregnant adults: HbAlc $<7 \%$, preprandial capillary plasma glucose between $80 \mathrm{mg} / \mathrm{dL}$ and $130 \mathrm{mg} / \mathrm{dL}$, and peak postprandial capillary plasma glucose $<180 \mathrm{mg} / \mathrm{dL}$ (4). The Diabetes Control and Complications Trial (DCCT) 
showed that adequate glycemic control in patients with DMl (e.g., fasting blood glucose levels up to $110 \mathrm{mg} / \mathrm{dL}$, postprandial glucose levels lower than $180 \mathrm{mg} / \mathrm{dL}$, and $\mathrm{HbAlc}<6.5 \%$ ) delays the onset and progression of microvascular complications, such as retinopathy, nephropathy, and neuropathy, and reduces the risk of any cardiovascular event by $42 \%$ and that of nonfatal infarction, stroke, and death by $57 \%$ (3).

The treatment of patients with $\mathrm{DMl}$ facilitates proper development in children and adolescents and improves the quality of life (QOL) of patients in general (5).

DMl control cannot be achieved solely via regular insulin use. Combining insulin use with diet and physical activity is important. In particular, adjusting insulin therapy to an individualized food plan is key to proper metabolic control (3). Conventional nutritional advice for patients with DMl is the same as for the general population. Specifically, a balanced nutrition with appropriate concentrations of macroand micronutrients should be based on the goals of treatment (i.e., total carbohydrate (CHO), 45\%-60\% of total energy intake (VET); protein, 15\%-20\% of VET; total fat (GT), up to $30 \%$ of VET; and minimum dietary fiber, $20 \mathrm{~g} /$ day or $14 \mathrm{~g} / 1000 \mathrm{kcal})(6)$.

In addition to conventional nutritional DMl treatments, carbohydrate counting (CHOC) is a meal planning tool that allows for great variation in food choices among individuals with DM (7), with the main objective of providing flexibility in food intake (8). Few dietary restrictions and the option to decide the number of meals (traditional treatment plans recommend eating six meals per day) may improve acceptance of the disease and overall QOL (9).

CHOC consists of measuring the amount of carbohydrates to be eaten during every meal in grams. Based on that count and preprandial blood glucose levels, the patient calculates the dose of fast or regular insulin they need before each meal $(10,11)$. This method can be used for any patient with diabetes in combination with the use of varying doses of rapidacting insulin or continuous subcutaneous insulin infusion (12). Two CHOC methods are widely used: listing carbohydrate equivalents (A) and measuring the carbohydrate in grams (B). In method A, foods are grouped so that each food portion chosen by the patient corresponds to $15 \mathrm{~g}$ of carbohydrate, classifying them as equivalents. Method B consists of the sum of carbohydrate grams in each food per meal based on information in food labels and tables (13).
To improve glycemic control and decrease the frequency of acute and chronic complications, CHOC is now recommended as another nutritional tool $(3,14)$.

Regarding the efficacy of the CHOC method in metabolic DMl control in the DCCT study, individuals who adjusted their pre-meal insulin doses based on carbohydrate counts had a $0.5 \%$ decrease in HbAlc compared to the group that used a fixed dose (15). Dias and cols. (16) showed that HbAlc levels were reduced in a group of 55 adult patients, and although the total daily dose of insulin increased, no weight gain was observed. Waller and cols. (17) also evaluated CHOC in children and adolescents with DMl and reported no changes in HbAlc, body mass index (BMI), or frequency of hypoglycemic episodes. However, the children and their parents showed an improvement in QOL.

We hypothesized that the CHOC method in adult individuals with DMl may be more effective and efficient for glycemic control and better improve QOL compared to conventional nutritional guidance.

This study aimed to evaluate the effectiveness and safety of CHOC in the treatment of adult patients with DMI using a systematic literature review.

\section{MATERIALS AND METHODS}

This review was performed according to Cochrane Methodology (18) and reported according to the PRISMA Statement (19).

\section{Eligibility criteria}

We included randomized controlled trials with at least three months of follow-up, and evaluation of outcomes in which patients were randomly divided into two groups, intervention or comparison. Data were interpreted based on patient-characteristics, intervention, comparison, and outcomes (PICO) as described below.

\section{Patients}

Patients consisted of men and women aged over 18 years old who had been diagnosed with DMl for at least six months and were not in the "honeymoon period", in which the pancreas can produce small amounts of insulin that can be enough to achieve adequate glycemic control at a daily dose of less than $0.5 \mathrm{IU}$ insulin/ $\mathrm{kg}$ in 24 hours. Patients had standard 
nutritional counseling with a professional nutritionist and took slow-acting or intermediate and multiple fast or regular insulin doses before meals (breakfast, lunch, and dinner) or continuous subcutaneous insulin infusion (CSII). Studies that included pregnant women, individuals with a BMI $>40 \mathrm{~kg} / \mathrm{m}^{2}$, kidney failure, or HbAlc $>14 \%$ were excluded from analysis.

\section{Intervention}

Individuals in the intervention group had nutritional counseling for $\mathrm{CHOC}$ to determine the amount of fast or regular insulin that they would need before each main meal.

\section{Comparison}

The comparison group included individuals who had conventional nutritional advice and used fixed doses of fast or regular insulin before meals.

\section{Outcomes}

Assessed outcomes were reduction in $\mathrm{HbAlc}$, frequency of severe hypoglycemia, improved QOL, body weight or BMI gain, lipid profile, and total daily dose of insulin. Validated questionnaires were used to evaluate QOL: Audit of Diabetes-Dependent Quality of Life (ADDQoL), Diabetes Treatment Satisfaction Questionnaire (DTSQ), and Diabetes Quality of Life Measure (DQoL).

\section{Search strategy and selection}

No language restriction was imposed. We searched the following electronic databases through November 30, 2016 to identify randomized clinical trials involving CHOC versus conventional nutritional advice in the treatment of DMl patients: Embase (1980-2016), PubMed (1966-2016), Lilacs (1982-2016), and the Cochrane Central Register of Controlled Trials (CENTRAL, the Cochrane Library, issue 2016). We also searched for ongoing clinical trials on the clinicaltrials. gov website. Medical Subject Heading terms used included "Type 1 Diabetes Mellitus", "Carbohydrates", "Nutrition Therapy", and "Randomized Controlled Trial".

Two reviewers (ECV and VSNN) independently screened the titles and abstracts identified in the literature search. Studies potentially eligible for inclusion in the review were selected for complete reading.

\section{Data extraction and risk of bias}

Both reviewers assessed the study quality and extracted data using an extraction template. For each trial, we assigned the risk of bias considering the quality scores for random sequence generation, allocation concealment, blinding of outcome assessment, and incomplete outcome data. We used the criteria described in the Cochrane Reviewer's Handbook (18) to classify these scores as adequate (low risk of bias), unclear, and inadequate (high risk of bias).

\section{Data synthesis and analysis}

We performed the meta-analysis by using a randomeffects model in Review Manager 5.3 software. For dichotomous outcomes, the relative risk was calculated with a $95 \%$ confidence interval and continuous variables were expressed as a weighted mean difference with 95\% confidence intervals. Potential causes of heterogeneity among studies were also analyzed. The $\mathrm{I}^{2}$ statistic was used to measure the impact of heterogeneity for each outcome (where an $\mathrm{I}^{2} \geq 50$ indicates a considerable level of heterogeneity) (18). When we found heterogeneity, we attempted to determine possible reasons for it via subgroup analysis or by examining individual studies.

\section{Quality assessment}

The quality of evidence per outcome measurement was graded according to the Grading of Recommendations Assessment, Development and Evaluation (GRADE) Working Group. The confidence of the GRADE system decreases if randomized studies have major limitations that may interfere with treatment effect estimates (20). These limitations include risk of bias for each study, inconsistency, indirectness, imprecision, and publication bias of each evaluated outcome per GRADE considerations.

\section{RESULTS}

From the database searches, 3190 articles were identified (Figure 1). Fifteen articles were potentially eligible for inclusion in the analysis and were selected for full review. Five of the 15 studies were included for analysis $(7,10,15,21,22)$. Of the 10 excluded studies, three were not randomized (23-25), three compared two different methods for mealtime insulin dosing; no group had conventional nutritional advice using a fixed dose of fast or regular insulin before meals $(8,26,27)$. In three studies, patients were children or adolescents (28-30), 
and one study compared three different possibilities of insulin self-adjustments, without a group using a fixed dose of fast or regular insulin before meals (31).

The baseline characteristics of study participants and eligibility criteria of the included studies are presented in Tables 1 and 2 , respectively. $\mathrm{P}$ values $<0.05$ were considered statistically significant.

Dafne and cols. (7) performed a single-center study in England. A total of 169 patients with DMl who had been diagnosed more than two years prior without chronic complications and intensive insulin therapy were randomized to $\mathrm{CHOC}$ or conventional nutritional treatment. The main outcome measures after a

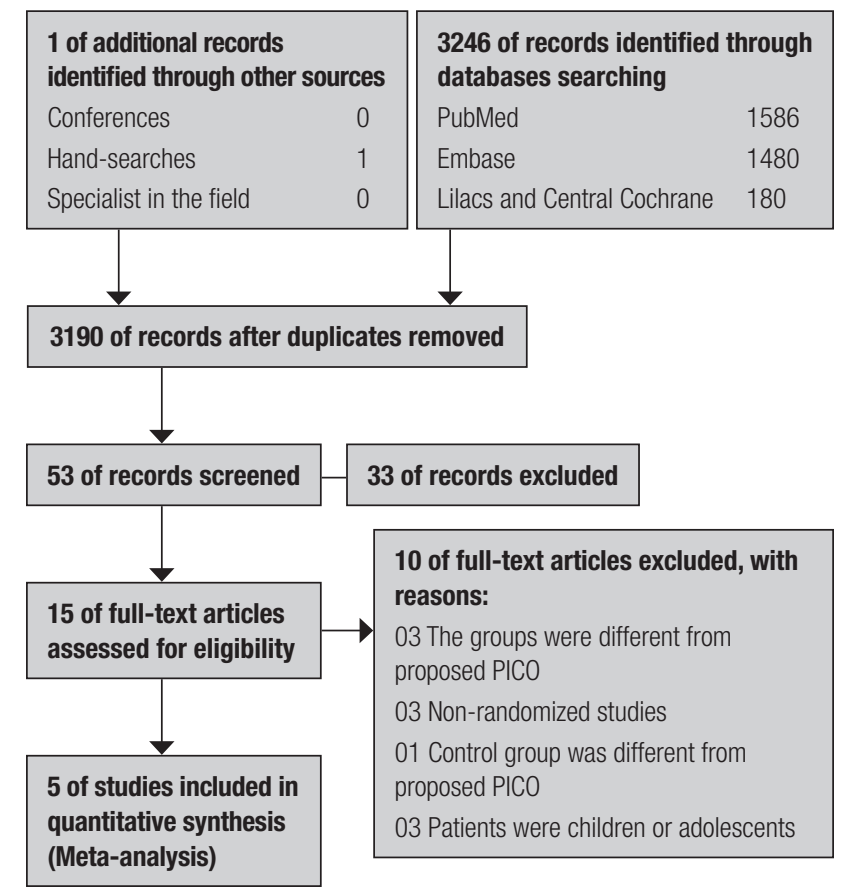

Figure 1. Flowchart for identifying eligible studies six-month follow-up were: HbAlc, severe hypoglycemia, and the impact of diabetes on QOL as assessed using the ADDQoL questionnaire.

Laurenzi and cols. (10) recruited patients from a clinic in Milan, Italy. A total of 61 adult patients with DMl who had been treated with CSII were randomly assigned to learn $\mathrm{CHOC}$ in the intervention group or to estimate pre-meal insulin doses empirically for six months. The main outcome measures were: $\mathrm{HbAlc}$, fasting glucose, BMI, waist circumference, daily insulin dose, hypoglycemic events, and analysis of QOL through the Diabetes-Specific Quality-of-life Scale, which evaluates individual treatment goals in patients with DMl.

In the study of Scavone and cols. (Italy) (21), 256 patients with $\mathrm{DMl}$ who had been diagnosed for more than five years were randomized to a CHOC group or a control group. Weight, BMI, HbAlc, lipid profile, uric acid, creatinine, microalbuminuria, daily insulin requirements, and number of episodes of hypoglycemia (blood glucose < $70 \mathrm{mg} / \mathrm{dL}$ ) were the main outcomes evaluated.

Schmidt and cols. (15) recruited patients from two centers in Denmark. The authors randomized 63 adults with $\mathrm{DMl}$ and poor metabolic control (HbAlc: $8.0 \%$ to $10.5 \%)$ to the CHOC or control groups for more than 12 months using analogues of basal and fast insulin. The main outcome measures were: change in HbAlc, weight, satisfaction with the treatment of diabetes, and perceived frequency of hyper- and hypoglycemia. The parameters were measured according to the Diabetes Treatment Satisfaction status version and version change questionnaires (DTSQs and DTSQc, respectively). QOL was analyzed using the ADDQoL questionnaire.

Table 1. Baseline characteristics of patients in each included study

\begin{tabular}{|c|c|c|c|c|c|c|c|}
\hline Study & $\begin{array}{l}\text { Number of } \\
\text { randomized } \\
\text { patients }\end{array}$ & Male/Female & Age (SD) & HbA1C (SD) & $\begin{array}{l}\text { Fasting Glucose } \\
\text { nmol/L (SD) }\end{array}$ & $\begin{array}{l}\text { BMI or weight (kg) } \\
\text { (SD) }\end{array}$ & Insulin dose (SD) \\
\hline Dafne, 2002 & $\begin{aligned} \mathrm{G} 1 & =84 \\
\mathrm{G} 2 & =85\end{aligned}$ & - & - & $\begin{array}{l}\mathrm{G} 1-9.4(1.2) \\
\mathrm{G} 2=9.3(1.1)\end{array}$ & - & $\begin{aligned} \mathrm{G} 1 & =80.5(1.7) \\
\mathrm{G} 2 & =77.4(13.4)\end{aligned}$ & - \\
\hline $\begin{array}{l}\text { Laurenzi, } \\
2011\end{array}$ & $\begin{aligned} \mathrm{G} 1 & =28 \\
\mathrm{G} 2 & =28\end{aligned}$ & $\begin{array}{l}\mathrm{G} 1=15 / 13 \\
\mathrm{G} 2=09 / 19\end{array}$ & $\begin{array}{l}\mathrm{G} 1=41.2(10.0) \\
\mathrm{G} 2=39.8(9.8)\end{array}$ & $\begin{array}{l}\mathrm{G} 1=7.9(0.9) \\
\mathrm{G} 2=8.1(1.5)\end{array}$ & - & $\begin{array}{c}\mathrm{G} 1=23.7(21-25.2) \\
\mathrm{G} 2=23.8(20.8-26.8)\end{array}$ & $\begin{array}{c}{ }^{* *} \mathrm{G} 1=36(24.5-49) \\
{ }^{* *} \mathrm{G} 2=33(28.5-39.5)\end{array}$ \\
\hline $\begin{array}{l}\text { Scavone, } \\
2010\end{array}$ & $\begin{array}{l}\mathrm{G} 1=100 \\
\mathrm{G} 2=156\end{array}$ & $\begin{array}{l}\mathrm{G} 1=49 / 51 \\
\mathrm{G} 2=74 / 82\end{array}$ & $\begin{array}{l}\mathrm{G} 1=39(11) \\
\mathrm{G} 2=39(11)\end{array}$ & $\begin{array}{l}\mathrm{G} 1=7.8(1.3) \\
\mathrm{G} 2=7.5(0.8)\end{array}$ & - & - & - \\
\hline $\begin{array}{l}\text { Schmidt, } \\
2012\end{array}$ & $\begin{aligned} \mathrm{G} 1 & =26 \\
\mathrm{G} 2 & =09\end{aligned}$ & $\begin{array}{l}\mathrm{G} 1=10 / 11 \\
\mathrm{G} 2=06 / 02\end{array}$ & $\begin{array}{l}\mathrm{G} 1=41(10) \\
\mathrm{G} 2=46(09)\end{array}$ & $\begin{array}{l}\mathrm{G} 1=9.2(0.6) \\
\mathrm{G} 2=9.1(0.7)\end{array}$ & - & - & $\begin{array}{l}{ }^{*} \mathrm{G} 1=0.6(0.2) \\
{ }^{*} \mathrm{G} 2=0.7(0.17)\end{array}$ \\
\hline Trento, 2009 & $\begin{aligned} \mathrm{G} 1 & =27 \\
\mathrm{G} 2 & =29\end{aligned}$ & $\begin{aligned} G 1 & =18 / 9 \\
G 2 & =12 / 17\end{aligned}$ & $\begin{array}{c}\mathrm{G} 1=37.33(12.6) \\
\mathrm{G} 2=36.76(7.9)\end{array}$ & $\begin{aligned} \mathrm{G} 1 & =7.6(1.3) \\
\mathrm{G} 2 & =7.7(1.24)\end{aligned}$ & $\begin{aligned} \mathrm{G} 1 & =9.64(5.17) \\
\mathrm{G} 2 & =9.05(5.08)\end{aligned}$ & $\begin{array}{l}\mathrm{G} 1=24.4(2.6) \\
\mathrm{G} 2=23.5(3.3)\end{array}$ & $\begin{aligned}{ }^{* *} \mathrm{G} 1 & =47.9(10.6) \\
{ }^{*} \mathrm{G} 2 & =45.7(12.6)\end{aligned}$ \\
\hline
\end{tabular}

G1: intervention group; G2: control group. * Daily insulin dose per kg; ${ }^{* \star}$ Total insulin dose (basal and bolus). - No information provided. 
Table 2. Length of follow-up, inclusion criteria, and outcomes of included studies

\begin{tabular}{|c|c|c|c|}
\hline Study & Follow-up & Inclusion criteria & Outcomes \\
\hline DAFNE, 2002 & 6 months & $\begin{array}{l}>18 \text { years of } \mathrm{HbA} 1 \mathrm{c} \text { from } 7.5 \% \text { to } 12 \% \text { and diagnosis greater } \\
\text { than } 2 \text { years without advanced complications }\end{array}$ & $\begin{array}{l}\text { Change in } \mathrm{HbA1C}(\mathrm{HPLC}) \text {, severe hypoglycemia and } \\
\text { hyperglycemia, quality of life (ADDQoL, DTSQ, and W-BQ12), } \\
\text { weight, blood pressure, lipid profile, injections, glucose } \\
\text { monitoring, and daily total dose of insulin }\end{array}$ \\
\hline Laurenzi, 2011 & $\begin{array}{l}3 \text { and } 6 \\
\text { months }\end{array}$ & $\begin{array}{l}\text { Age between } 18 \text { and } 65 \text { years and treatment with continuous } \\
\text { insulin infusion pump for more than } 3 \text { months }\end{array}$ & $\begin{array}{l}\text { Change in HbA1C (HPLC), hypoglycemia, quality of life } \\
\text { (DSQOLS), BMI, waist, fasting glucose, and daily insulin dose }\end{array}$ \\
\hline Scavone, 2010 & 9 months & Diagnosis of type 1 diabetes mellitus over 5 years & $\begin{array}{l}\text { Changes in HbA1c, hypoglycemia, daily insulin dose, weight, } \\
\text { lipid profile, creatinine, and microalbuminuria }\end{array}$ \\
\hline Schmidt, 2012 & 4 months & $\begin{array}{l}\text { Age between } 18 \text { and } 65 \text { years, poor metabolic control, } \\
\text { diabetes duration over } 12 \text { months, and use of basal and fast } \\
\text { analogue insulin. }\end{array}$ & $\begin{array}{l}\text { Changes in HbA1C, severe hypoglycemia, treatment } \\
\text { satisfaction and perceived frequency of hypo- and } \\
\text { hyperglycemia (DTSQs and DTSQc), quality of life (ADDQoL), } \\
\text { change in the perception of problem areas (PAID), and change } \\
\text { in fear of hypoglycemia (HFS) }\end{array}$ \\
\hline Trento, 2009 & 30 months & $\begin{array}{l}\text { Age }<70 \text { years, onset of diabetes before } 30 \text { years of age, and } \\
\text { onset of insulin use within the first year of the diagnosis }\end{array}$ & $\begin{array}{l}\text { Changes in HbA1C (HPLC), severe hypoglycemia and } \\
\text { hyperglycemia, quality of life (DQOL, GISED, CSI), BMI, and lipid } \\
\text { profile and fasting glucose }\end{array}$ \\
\hline
\end{tabular}

Trento and cols. (22) included 56 patients with $\mathrm{DMl}$ who had all been diagnosed before age 30 years. Twenty-seven subjects were randomized to a CHOC program and the remaining patients were assigned to the control group. Body weight, fasting glucose, HbAlc, total cholesterol, high-density lipoprotein cholesterol, triglycerides and creatinine, frequency of hypoglycemia, and QOL were the main outcome measures.

\section{Risk of bias}

Dafne and cols. (7) and Laurenzi and cols. (10) randomized patients using a computer-generated random number. Schmidt and cols. (15) performed the random distribution with a $1: 3: 3$ ratio in blocks of 14 with sealed, opaque envelopes containing group assignments. Scavone and cols. (21) and Trento and cols. (22) did not describe how the randomization sequence was generated.

Only Dafne, Laurenzi, and Schmidt described allocation concealment and as such were classified as low risk of bias. The other two studies did not provide any information regarding the allocation process.

Most of the studies included did not report blinding for outcome evaluation. However, except for severe hypoglycemia, most were laboratory assessments, which were not susceptible to bias. QOL questionnaires were self-applied and could not be blinded.

Only Laurenzi and cols. reported that patients who did not complete the treatment regimen were included in the final analysis (low risk) (10). Trento and cols. (22) reported that all participants completed the treatment (low risk). In the study of Dafne and cols. (7), 28 patients were lost to follow-up and were not included in the final analysis, although the number of patients who were lost was not significantly different between the groups ( 15 in the intervention group and 13 in the control group) (low risk). Scavone and cols. (21) had a $27 \%$ loss of patients in the intervention group, and they were not included in the final analysis (high risk). Schmidt and cols. (15) had a 19\% loss, and these patients were not included in the final analysis (high risk).

\section{Meta-analysis of outcomes}

The five studies included analyzed changes in HbAlc levels at the end of the study. Meta-analysis showed that the final $\mathrm{HbAlc}$ was significantly lower in the CHOC group than in the control group (mean difference, random, 95\% CI: $-0.49(-0.85,-0.13), \mathrm{p}=0.006, \mathrm{I}^{2}=$ $72 \%$ ) (Figure 2).

In the four trials, the number of patients who experienced at least one episode of severe hypoglycemia can be assessed $(7,15,21,22)$. The meta-analysis of this outcome was not significantly different between groups (risk ratio, random, 95\% CI: $0.94(0.55,1.6), \mathrm{p}=0.82$, $\mathrm{I}^{2} 0 \%$ ) (Figure 3).

Regarding QOL, two studies $(7,15)$ used the ADDQoL instrument, but no difference was noted between groups (mean difference, random, 95\% CI: $\left.-0.23(-1.4,0.94), \mathrm{p}=0.7, \mathrm{I}^{2}=84 \%\right)$. The same studies also used the DTSQs questionnaire and found no difference between groups (mean difference, random, 95\% CI: 3.53 (-7.11, 14.16), $\left.\mathrm{p}=0.52, \mathrm{I}^{2}=95 \%\right)$. 


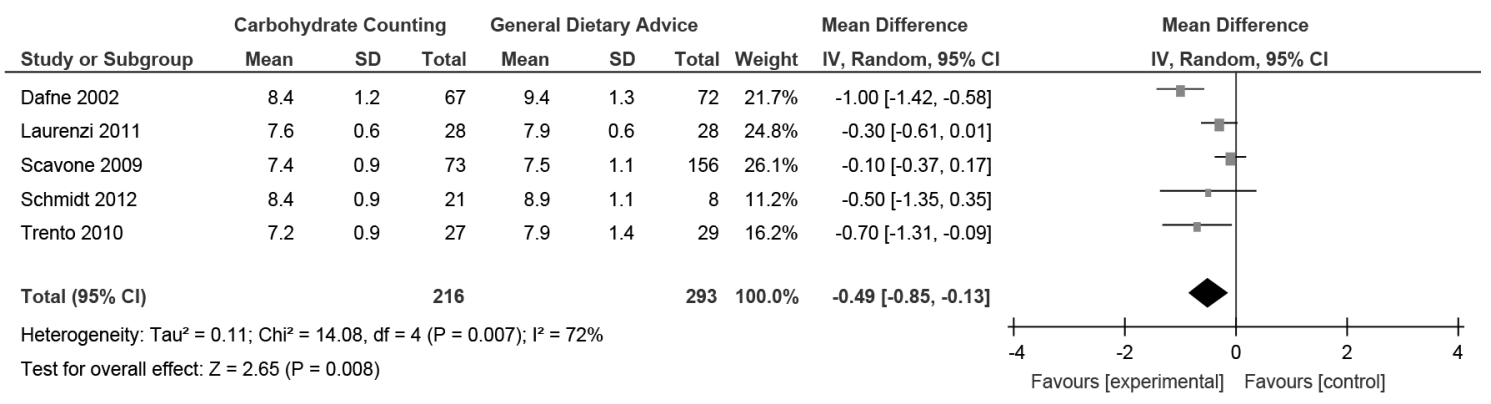

Figure 2. Meta-analysis of change in $\mathrm{HbA1C}$.

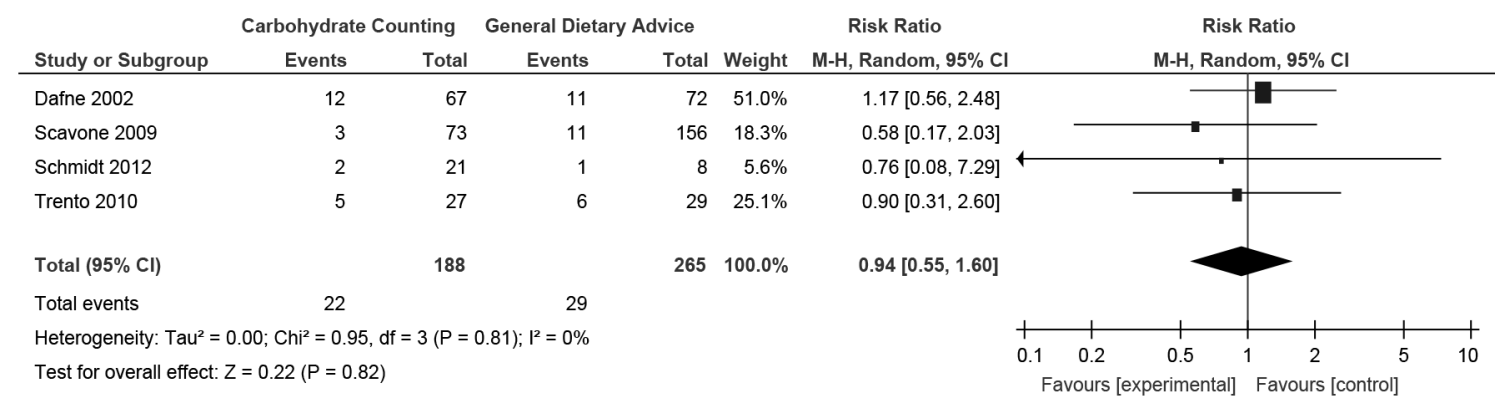

Figure 3. Meta-analysis of episodes of severe hypoglycemia.

We plotted the QOL outcomes using different questionnaires (DQOL and DTSQs) cited in three studies $(7,15,22,23)$ and found no significant differences between groups (std. mean difference, random, 95\% CI: $\left.0.64(-0.7,1.98), \mathrm{p}=0.35, \mathrm{I}^{2}=94 \%\right)$.

Meta-analysis of total cholesterol, HDL-C, and triglycerides could only be performed based on the results reported in the study of Dafne and cols. (7) and Trento and cols. (22); no significant differences were noted among groups.

According to the GRADE, the quality of evidence of the primary outcomes was moderate for changes in $\mathrm{HbAlc}$, low for episodes of severe hypoglycemia, and very low for QOL (Table 3).

\section{DISCUSSION}

Most individuals with DMl have a hard time managing fasting and postprandial blood glucose levels. In addition, many patients with this disease have poor compliance to dietary advice.

Poor disease control can increase the risk of complications, such as retinopathy and other microvascular conditions (3). Ahola and cols. (32) reported that only one-third of patients maintained controlled blood glucose levels after a meal and that approximately $40 \%$ experienced frequent hyperglycemia despite having seemingly normal metabolic control. As such, the search for tools to improve these health issues

Table 3. Quality of evidence of primary outcomes according to GRADE approach

\begin{tabular}{|c|c|c|c|c|c|c|c|c|}
\hline Outcomes & Risk of bias & Inconsistency & Indirectness & Imprecision & $\begin{array}{l}\text { Publication } \\
\text { bias }\end{array}$ & $\begin{array}{c}\text { Intervention vs } \\
\text { comparator } 95 \% \mathrm{Cl}\end{array}$ & $\begin{array}{l}\text { Participants } \\
\text { (studies) }\end{array}$ & $\begin{array}{l}\text { Quality of } \\
\text { evidence }\end{array}$ \\
\hline $\begin{array}{l}\text { Severe } \\
\text { hypoglycemia }\end{array}$ & Serious $^{*}(-1)$ & No & No & Serious $(-1)^{\star \star \star}$ & Unlikely & RR 0.92 (0.54 a 1.56) & $453(4)$ & +Low \\
\hline $\begin{array}{l}\text { Quality of Life } \\
\text { (ADDQoL) }\end{array}$ & Serious $^{*}(-1)$ & Serious $(-1)^{\star *}$ & No & Serious $(-1)^{\star \star \star \star}$ & Unlikely & MD $3.53(-7,11$ a 14.16) & $168(2)$ & +++Very low \\
\hline Change in $\mathrm{HbA} 1 \mathrm{c}$ & Serious $^{*}(-1)$ & No & No & No & Unlikely & MD $-0.45(-0.77,-0.13)$ & $535(5)$ & + Moderate \\
\hline
\end{tabular}

* Most of the included studies did not report about allocation concealment, and they did not perform an intention-to-treat analysis. ${ }^{\star \star}$ Presence of statistical heterogeneity $\left(l^{2}>75 \%\right)$. ${ }^{\star \star \star} 95 \% \mathrm{Cl}$ overlaps no effect but includes important benefit or important harm. ${ }^{\star \star \star \star}$ Optimal information size criterion was not meet. ADDQOL: Audit of Diabetes - Dependent Quality of Life. RR: Relative risk. MD: Mean difference. ++ Low evidence: The authors are not confident in the effect estimate, and the true value may be substantially different from it. ++ Very low evidence: The authors do not have any confidence in the estimate, and it is likely that the true value is substantially different from it. + Moderate evidence: Further research is likely to have an important impact on our confidence in the estimate of effect and may change the estimate. 
has increased, and CHOC may be the only effective option for adherence to dietary requirement in patients with variable dietary habits.

To reduce postprandial blood glucose, protocols from the DAPHNE program and the Diabetes Teaching and Treatment have used the CHOC method for nutritional counseling (33). Some studies reported that $\mathrm{CHOC}$ can provide better glycemic control and lead to an improved QOL for patients $(3,17)$. Patients using this method have greater flexibility in food choices without the concern of postprandial hyperglycemia given that the amount of carbohydrates ingested is considered when computing the amount of insulin to be administered before meals.

In daily clinical practice, the goal is to maintain good long-term disease control, prevent chronic complications from DM, and reduce the frequency of hypoglycemia to improve overall QOL. We performed a systematic review focusing on the efficacy and safety of the CHOC method in the management of patients with $\mathrm{DMl}$. We included randomized trials that compared the CHOC method with conventional nutritional guidance in the treatment of patients with DMI.

Five studies met the established inclusion criteria and were included in qualitative and quantitative analyses. Most of the studies assessed changes in $\mathrm{HbAlc}$, frequency of hypoglycemia, and QOL as primary endpoints. Meta-analysis showed a significant difference in final HbAlc favoring the intervention group.

A criticism of HbAlc is that even though levels are associated with the frequency of chronic complications and rate of morbidity and mortality, the value of this laboratory outcome is often discussed without considering glycemic variability. Although it is important for HbAlc levels to be lower than the cutoff values that indicate disease control, blood glucose levels can range from high to low. An association between glycemic variability and development of micro diabetes-related complications has been shown in type $2 \mathrm{DM}$ and has also been studied as a possibility in DMl (34). If confirmed, HbAlc values in DMl would be inadequate to determine the superiority of one treatment to another. However, in this present review, the frequency of hypoglycemia was the same between the groups, which means that the relevance of lowering HbAlc would not be reduced.

Regarding QOL outcomes, several different instruments were used in the studies included, which negatively affected the single meta-analysis of this parameter. However, independent of the instrument used, an improvement in QOL from baseline compared with the final visit in most of the studies was noted, although no difference was observed between the intervention and control groups. Improvement in QOL can be more associated with follow-up programs and nutritional guidance than the initial methods evaluated.

Applying the GRADE approach for the outcomes "change in HbAlc" and "severe hypoglycemia," it was necessary to rate down for the risk of bias because five out of the six studies lost patients to follow-up without an intention to treat analysis. In addition, concealment allocation and randomization processes were unclear in two of the studies. Similarly, imprecision was rated down for both, because optimal information size criterion was not met and 95\% CI overlaps no effect but includes important benefit or important harm, respectively. Rating down for indirectness and publication bias was unnecessary. The quality of evidence for "change in HbAlc" and "severe hypoglycemia" was moderate and low, respectively, indicating that further research is likely to have an important impact on our confidence and authors are not confident in the effect estimate. The quality of the evidence regarding QOL outcomes was very low, and any estimate of its effect is uncertain.

Bell and cols. (35) recently published a similar systematic review. They included a study that was not included in our analysis because the comparison groups were different from the proposed PICO (31) They also included another study that we excluded because patients in the control group were predominantly children, and they were provided nutritional guidance of low glycemic index (36). Finally, Bell and cols. did not use the GRADE. The results of the previous study favored the intervention group, and the authors interpreted the results in support of recommending CHOC instead of general dietary advice in patients with DMl.

Considering the studies included in the present systematic review, the meta-analysis showed evidence favoring the use of CHOC in the management of adult patients with DMl. However, this benefit was limited to final $\mathrm{HbAlc}$, which was significantly lower in the CHOC group than in the control group. Therefore, new randomized trials with greater internal and external validation and long-term outcomes are needed to analyze whether or not a significant difference exists between these two nutritional guidance tools in terms 
of other important diabetes-related outcomes, such as mortality, QOL, and diabetes complications.

Disclosure: no potential conflict of interest relevant to this article was reported.

\section{REFERENCES}

1. American Diabetes Association. Diagnosis and classification of diabetes mellitus. Diabetes Care. 2014;37 Suppl 1:S81-90.

2. DIAMOND Project Group. Incidence and trends of childhood type 1 diabetes worldwide 1990-1999. Diabet Med. 2006;23(8):857-66.

3. Diabetes Control and Complications Trial Research Group, Nathan DM, Genuth S, Lachin J, Cleary P, Crofford O, Davis M, et al. The effect of intensive treatment of diabetes on the development and progression of long-term complications in insulin-dependent diabetes mellitus. N Engl J Med. 1993;329(14):977-86.

4. American Diabetes Association. 6. Glycemic Targets. Diabetes Care. 2017;40(Suppl 1):S48-S56.

5. Diet, nutrition and the prevention of chronic diseases. World Health Organ Tech Rep Ser. 2003;916:i-viii, 1-149, backcover.

6. Evert AB, Boucher JL, Cypress M, Dunbar SA, Franz MJ, MayerDavis EJ, et al. Nutrition therapy recommendations for the management of adults with diabetes. Diabetes Care. 2014;37 Suppl 1:S120-43.

7. DAFNE Study Group. Training in flexible, intensive insulin management to enable dietary freedom in people with type 1 diabetes: dose adjustment for normal eating (DAFNE) randomised controlled trial. BMJ. 2002;325(7367):746.

8. Rabasa-Lhoret R, Garon J, Langelier H, Poisson D, Chiasson JL. Effects of meal carbohydrate content on insulin requirements in type 1 diabetic patients treated intensively with the basalbolus (ultralente-regular) insulin regimen. Diabetes Care. 1999;22(5):667-73.

9. Rossi MC, Nicolucci A, Di Bartolo P, Bruttomesso D, Girelli A, Ampudia FJ, et al. Diabetes Interactive Diary: a new telemedicine system enabling flexible diet and insulin therapy while improving quality of life: an open-label, international, multicenter, randomized study. Diabetes Care. 2010;33(1):109-15.

10. Laurenzi A, Bolla AM, Panigoni G, Doria V, Uccellatore A, Peretti $E$, et al. Effects of carbohydrate counting on glucose control and quality of life over 24 weeks in adult patients with type 1 diabetes on continuous subcutaneous insulin infusion: a randomized, prospective clinical trial (GIOCAR). Diabetes Care. 2011;34(4):823-7.

11. Hegar K, Heiber S, Brandle M, Christ E, Keller U. Carbohydrate counting of food. Swiss Med Wkly. 2011;141:w13224.

12. Bell KJ, King BR, Shafat A, Smart CE. The relationship between carbohydrate and the mealtime insulin dose in type 1 diabetes. $J$ Diabetes Complications. 2015;29(8):1323-9.

13. Nutricionistas Membros do Departamento de Nutrição da SBD. Manual de contagem de carboidratos para pessoas com diabetes. Sociedade Brasileira de Diabetes, 2016.

14. Diretrizes da Sociedade Brasileira de Diabetes (2015-2016). Rio de Janeiro: AC Farmacêutica Ltda.; 2016. Princípios para Orientação Nutricional no Diabetes Mellitus; p. 91-110.

15. Schmidt S, Meldgaard M, Serifovski N, Storm C, Christensen TM, Gade-Rasmussen B, et al. Use of an automated bolus calculator in MDI-treated type 1 diabetes: the BolusCal Study, a randomized controlled pilot study. Diabetes Care. 2012;35(5):984-90.

16. Dias VM, Pandini JA, Nunes RR, Sperandei SL, Portella ES, Cobas RA, et al. Effect of the carbohydrate counting method on glycemic control in patients with type 1 diabetes. Diabetol Metab Syndr. 2010;2:54.
17. Waller H, Eiser C, Knowles J, Rogers N, Wharmby S, Heller S, et al. Pilot study of a novel educational programme for 11-16 year olds with type 1 diabetes mellitus: the KICk-OFF course. Arch Dis Child. 2008;93(11):927-31.

18. Cochrane Handbook for Systematic Reviews of Interventions Version 5.1.0 [updated March 2011] [Internet]. 2011.

19. Liberati A, Altman DG, Tetzlaff J, Mulrow C, Gotzsche PC, loannidis JP, et al. The PRISMA statement for reporting systematic reviews and meta-analyses of studies that evaluate health care interventions: explanation and elaboration. Ann Intern Med. 2009;151(4):W65-94.

20. Guyatt GH, Oxman AD, Kunz R, Vist GE, Falck-YtterY, Schünemann HJ; GRADE Working Group. What is "quality of evidence" and why is it important to clinicians? BMJ. 2008;336(7651):995-8.

21. Scavone G, Manto A, Pitocco D, Gagliardi L, Caputo S, Mancini $\mathrm{L}$, et al. Effect of carbohydrate counting and medical nutritional therapy on glycaemic control in Type 1 diabetic subjects: a pilot study. Diabet Med. 2010;27(4):477-9.

22. Trento M, Trinetta A, Kucich C, Grassi G, Passera P, Gennari S, et al. Carbohydrate counting improves coping ability and metabolic control in patients with Type 1 diabetes managed by Group Care. J Endocrinol Invest. 2011;34(2):101-5.

23. Bao J, Gilbertson HR, Gray R, Munns D, Howard G, Petocz P, et al. Improving the estimation of mealtime insulin dose in adults with type 1 diabetes: the Normal Insulin Demand for Dose Adjustment (NIDDA) study. Diabetes Care. 2011;34(10):2146-51.

24. Chiesa G, Piscopo MA, Rigamonti A, Azzinari A, Bettini S, Bonfanti $\mathrm{R}$, et al. Insulin therapy and carbohydrate counting. Acta Biomed. 2005;76 Suppl 3:44-8.

25. Dubé MC, Lavoie C, Galibois I, Weisnagel SJ. Nutritional strategies to prevent hypoglycemia at exercise in diabetic adolescents. Med Sci Sports Exerc. 2012;44(8):1427-32.

26. Rossetti P, Ampudia-Blasco FJ, Laguna A, Revert A, Vehì J, Ascaso $\mathrm{JF}$, et al. Evaluation of a novel continuous glucose monitoringbased method for mealtime insulin dosing - the iBolus - in subjects with type 1 diabetes using continuous subcutaneous insulin infusion therapy: a randomized controlled trial. Diabetes Technol Ther. 2012;14(11):1043-52.

27. Gilbertson HR, Brand-Miller JC, Thorburn AW, Evans S, Chondros $P$, Werther GA. The effect of flexible low glycemic index dietary advice versus measured carbohydrate exchange diets on glycemic control in children with type 1 diabetes. Diabetes Care. $2001 ; 24(7): 1137-43$.

28. Gökşen D, Atik Altınok Y, Ozen S, Demir G, Darcan S. Effects of carbohydrate counting method on metabolic control in children with type 1 diabetes mellitus. J Clin Res Pediatr Endocrinol. 2014;6(2):74-8.

29. Albuquerque $I Z$, Stringhini SMF, Marques RMB, Mundim CA, Rodrigues MLD, Campos MRH. Carbohydrate counting, nutritional status and metabolic profile of adolescents with type 1 diabetes mellitus. Sci Med. 2014;24(4).

30. Enander R, Gundevall C, Strömgren A, Chaplin J, Hanas R. Carbohydrate counting with a bolus calculator improves postprandial blood glucose levels in children and adolescents with type 1 diabetes using insulin pumps. Pediatr Diabetes. 2012;13(7):545-51.

31. Kalergis M, Pacaud D, Strychar I, Meltzer S, Jones PJ, Yale JF. Optimizing insulin delivery: assessment of three strategies in intensive diabetes management. Diabetes Obes Metab. 2000;2(5):299-305.

32. Ahola AJ, Mäkimattila S, Saraheimo M, Mikkilä V, Forsblom C, Freese R, Groop PH; FinnDIANE Study Group. Many patients with type 1 diabetes estimate their prandial insulin need inappropriately. J Diabetes. 2010;2(3):194-202. 
33. Speight J, Amiel SA, Bradley C, Heller S, Oliver L, Roberts S, et al. Long-term biomedical and psychosocial outcomes following DAFNE (Dose Adjustment For Normal Eating) structured education to promote intensive insulin therapy in adults with sub-optimally controlled type 1 diabetes. Diabetes Res Clin Pract. 2010;89(1):22-9.

34. American Diabetes Association. Executive summary: standards of medical care in diabetes - 2011. Diabetes Care. 2011;34 Suppl 1:S4-10.
35. Bell KJ, Barclay AW, Petocz P, Colagiuri S, Brand-Miller JC. Efficacy of carbohydrate counting in type 1 diabetes: a systematic review and meta-analysis. Lancet Diabetes Endocrinol. 2014;2(2):133-40.

36. Gilbertson HR, Thorburn AW, Brand-Miller JC, Chondros P, Werther GA. Effect of low-glycemic-index dietary advice on dietary quality and food choice in children with type 1 diabetes. Am J Clin Nutr. 2003;77(1):83-90. 